\title{
An Analyzing of the Relationship Between Exercise Addiction and Obesity Awareness
}

OPEN ACCESS

Volume: 9

Special Issue: 2

Month: September

Year: 2021

E-ISSN: 2582-1334

Received: 13.07.2021

Accepted: 24.08.2021

Published: 15.09.2021

Citation:

Zengin, Samet, and Fatih

Kırkbir. "An Analyzing of the Relationship Between Exercise Addiction and Obesity Awareness." Shanlax International Journal of Education, vol. 9, no. S2, 2021, pp. $45-51$.

\section{DOI:}

https://doi.org/10.34293/ education.v9iS2-Sep.4369

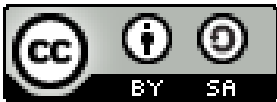

This work is licensed under a Creative Commons Attribution-ShareAlike 4.0 International License

\author{
Samet Zengin \\ Trabzon University, Turkey \\ https://orcid.org/0000-0002-5370-5878
}

\section{Fatih Kurkbir}

Karadeniz Technical University, Turkey

https://orcid.org/0000-0002-1678-5311

\begin{abstract}
Depending on the developing technology, individuals started to pursue a less active lifestyle. The sedentary lifestyle has brought along many health problems. One of these health problems is obesity. Awareness of obesity is important for individual health. One of the applications that can be implemented to cope with obesity is exercise. This study aims to analyze the relationship between university students' exercise addiction and obesity awareness. Therefore, 249 university students (132 males, 117 females) participated in the study. In the study, the "Exercise Addiction Scale" developed by Tekkurşun-Demir, Hazar and Cicioğlu (2018) and the "Obesity Awareness" scale developed by Allen (2011) and adapted to Turkish culture by Kafkas and Özen (2014) were used as data collection tools. Data were analyzed with descriptive statistical methods, $t$-test for independent groups and one-way variance (ANOVA). Correlation test was employed to determine the relationship between exercise addiction and obesity awareness. As a result of the research, it was determined that students' awareness of exercise addiction and obesity was at a moderate level. It was determined that exercise addiction had a significant effect on average the number of steps taken per day. Besides, it was determined that there was a low level of a positive relationship between exercise addiction and obesity awareness.
\end{abstract}

Keywords: Student, Exercise addiction, Obesity awareness.

\section{Introduction}

Exercise is a set of regular, planned and repetitive physical activities aimed at protecting or improving one or more components of physical fitness (Özer, 2013). Physical activity, on the other hand, is defined as all kinds of physical movements that require energy expenditure above the basal level by contraction of skeletal muscles (Pitta et al., 2006). Exercise addiction is defined as an individual's inability to control himself and exercise excessively despite obstacles and adverse situations (Adams, 2009). Increasing exercise duration, intensity and frequency, not spending time for family and friends to exercise, perceiving and planning their life around exercise are important symptoms of exercise addiction (Hausenblas \& Downs, 2002). It is stated that exercise addiction is associated with factors such as personality traits, psychological factors, physiological factors, exercise type, gender and year of participation in exercise (Bavl1 et al., 2011). Various reasons can be suggested for exercising. Some individuals exercise for the protection of mental health while others exercise for the protection of physical health. Furthermore, it is beneficial to exercise in maintaining both physical and mental health. There are many concepts related to exercise. One of these concepts is obesity awareness. 
Obesity is an important risk factor that causes increased cardiovascular diseases (Jacobs et al., 2010). It is known that the diet of the individual plays an important role in the development of obesity starting from the first years of life. Besides, it is known that many factors such as age, gender, environmental, biochemical, sociocultural, psychological and genetic factors lead to the formation of obesity (Tam \& Çakır, 2012). Bayraktar states that, by providing consultancy services on the causes and health risks of obesity, awareness and motivation of people can be increased (Bayraktar, 2010). Obesity is a chronic disease that occurs when the energy taken into the body via nutrients is more than the energy consumed, and it is characterized by the increase in the body fat mass compared to the lean body mass (Lim et al., 2015). Accordingly, some studies have been conducted (O'Dea \& Wilson2006; Lee et al., 2009; Murphy \& Polivka, 2007) to measure the obesity awareness in the society and to prevent the incidence of obesity in the society.

Obesity affects individual life negatively. It harms both mental and physical health. Obesity awareness is important at the point of taking precautions against obesity. Exercise contributes positively to obesity. Based on this idea, the current study examines the relationship between university students' exercise addiction and obesity awareness. Therefore, answers to some questions were sought. (1) What is the level of obesity awareness and exercise addiction of university students? (2) Do obesity awareness and exercise addiction have a significant effect on gender, the number of weekly exercises and the daily average number of steps? (3) Is there a significant relationship between exercise addiction and obesity awareness?

\section{Method \\ Study Group}

A total of 249 students studying in different departments participated in the current study. Of these students, 132 are male and 117 are female.

\section{Data Collection Tools}

Two scales were used as data collection tools in the study. These are the "Exercise Addiction Scale" developed by Tekkurşun-Demir, Hazar \& Cicioğlu
(2018) and the "Obesity Awareness" scale developed by Allen (2011) and adapted to Turkish culture by Kafkas \& Özen (2014).

\section{Exercise Addiction Scale}

The exercise addiction scale consists of 17 items in 5-point Likert-type. There are three subdimensions of the scale called Excessive Focus and Emotion Change, Postponement of Individual-Social Needs and Conflict, and Tolerance Development and Passion. The scale is scored as " $1=$ I Strongly Disagree", " $2=$ I Partially Disagree", " $3=$ I Moderately Agree", "4= I Agree", "5= I Strongly Agree". The score ranges are evaluated as "1-17 normal group, 18-34 low-risk group, 35-51 risk group, 52-69 addicted group, 70-85 highly addicted group" (Kafkas \& Özen, 2014).

\section{Obesity Awareness Scale}

The obesity awareness scale consists of 20 items in a 4-point Likert type. The scale has three sub-dimensions as obesity awareness, nutrition awareness, and physical activity awareness. The scale is scored as " $1=$ I Strongly Disagree", " $2=$ I Disagree", "3= I Agree", "4= I Totally Agree". The increase in the average scores obtained indicates that awareness has increased.

\section{Collection and Scoring of Data}

The scales used as data collection tools in the study were applied to 249 students via an online questionnaire, and the data of the research were obtained. Answers to exercise addiction were scored as $1, \ldots, 5$ from the most negative option to the most positive option. The answers to obesity awareness were scored as $1, \ldots 4$. The average scores of all scales and their sub-dimensions were calculated by taking the average of the items they included.

\section{Statistical Methods Used in Research}

The normality assumption of the data obtained was tested with Skewness, Kurtosis. In comparing exercise addiction and obesity awareness scores of university students, independent groups t-test was used for variables consisting of two categories while One-way Analysis of Variance-ANOVA was used for variables consisting of three or more categories. As a result of ANOVA, multiple comparison (Post Hoc.) 
test, Tukey was used to determine which groups the difference appeared. Besides, a correlation analysis was performed to determine the relationship between exercise addiction and obesity awareness.

Table 1: Reliability (Cronbach's Alpha) Coefficients of Scales

\begin{tabular}{|c|c|c|}
\hline Scales & $\begin{array}{c}\text { Cronbach's } \\
\text { Alpha }\end{array}$ & $\begin{array}{c}\text { Number } \\
\text { of Items }\end{array}$ \\
\hline Exercise Addiction & 0.923 & 17 \\
\hline Obesity Awareness & 0.761 & 20 \\
\hline
\end{tabular}

Reliability coefficients of exercise addiction and obesity awareness scales are shown in Table 1.
The reliability coefficient of exercise addiction (Cronbach's Alpha) is 0.923. The reliability coefficient of obesity awareness is 0.761 . The literature contains reliability coefficient values.

In the literature, the reliability coefficient is stated to be $0.81<\alpha 1.00$ (high reliability), $0.61 \alpha 0.80$ (medium reliability), $0.41 \alpha 0.60$ (low reliability), and 0.00 0.40 (unreliable) (Cortina, 1993; Streiner, 2003). According to the information in the literature, the exercise addiction reliability coefficient of the current study is of high reliability, and obesity awareness reliability coefficient is of medium reliability.

\section{Findings}

Table 2: Descriptive Statistics on Scale and Sub-Dimensions

\begin{tabular}{|l|c|c|c|c|c|}
\hline \multicolumn{1}{|c|}{ The Scale and Sub-Dimensions } & N & Mean & $\begin{array}{c}\text { Std. } \\
\text { Deviation }\end{array}$ & Skewness & Kurtosis \\
\hline Excessive Focus and Emotion Change & 249 & 3.40 & 6.68 & -.469 & -.448 \\
\hline Postponement of Individual-Social Needs and Conflict & 249 & 2.26 & 5.95 & .852 & .161 \\
\hline Tolerance Development and Passion & 249 & 2.58 & 4.55 & .323 & -.871 \\
\hline Exercise Addiction Total & 249 & 2.81 & 15.01 & .246 & -.447 \\
\hline Obesity Awareness & 249 & 3.15 & 3.97 & -.349 & .024 \\
\hline Nutrition awareness & 249 & 3.37 & 2.73 & -1.044 & 1.479 \\
\hline Physical activity awareness & 249 & 3.11 & 2.00 & -.288 & .263 \\
\hline Obesity Awareness Total & 249 & 3.20 & 7.20 & -.736 & .665 \\
\hline
\end{tabular}

In determining whether the total scores obtained from Exercise Addiction, Obesity Awareness and sub-dimensions show normal distribution, skewness and kurtosis values were taken into consideration. According to a criterion accepted in the literature, the skewness and kurtosis coefficients

between -1.5 and 1.5 indicate that the variables have normal distribution (Tabachnick and Fidell, 2013). Accordingly, considering the skewness and kurtosis values of both scales and sub-dimensions, it can be accepted that these variables have a normal distribution.

Table 3: Descriptive Statistics on Exercise Addiction and its Sub-Dimensions (T-test, ANOVA)

\begin{tabular}{|c|c|c|c|c|c|c|c|c|c|}
\hline \multirow[b]{2}{*}{ Gender } & \multicolumn{3}{|c|}{$\begin{array}{l}\text { Excessive Focus and } \\
\text { Emotion Change }\end{array}$} & \multicolumn{3}{|c|}{$\begin{array}{l}\text { Postponing Individual- } \\
\text { Social Needs and Conflict }\end{array}$} & \multicolumn{3}{|c|}{$\begin{array}{c}\text { Tolerance Development } \\
\text { and Passion }\end{array}$} \\
\hline & $\mathrm{X}$ & sd & $\mathbf{t}$ & $\mathrm{X}$ & sd & $\mathbf{t}$ & $\mathrm{X}$ & sd & $\mathbf{t}$ \\
\hline Male & 3.47 & 0.96 & \multirow{2}{*}{1.134} & 2.37 & 0.98 & \multirow{2}{*}{1.820} & 2.76 & 1.14 & \multirow{2}{*}{$2.602 *$} \\
\hline Female & 3.33 & 0.94 & & 2.14 & 0.99 & & 2.39 & 1.10 & \\
\hline $\begin{array}{c}\text { How many days a week do } \\
\text { you exercise? }\end{array}$ & $X$ & sd & $\mathbf{F}$ & $\mathrm{X}$ & sd & $\mathbf{F}$ & $X$ & sd & F \\
\hline $0-2$ day (s) & 3.22 & 0.97 & \multirow{3}{*}{$10.732 * *$} & 2.16 & 1.03 & \multirow{3}{*}{2.383} & 2.45 & 1.16 & \multirow{3}{*}{$3.432 *$} \\
\hline 3-5 days & 3.80 & 0.73 & & 2.38 & 0.89 & & 2.86 & 1.03 & \\
\hline 6-7 days & 3.25 & 1.14 & & 2.60 & 0.93 & & 2.50 & 1.20 & \\
\hline
\end{tabular}




\begin{tabular}{|c|c|c|c|c|c|c|c|c|c|}
\hline $\begin{array}{c}\text { How many thousand steps } \\
\text { do you take per day? }\end{array}$ & $\mathrm{X}$ & sd & $\mathbf{F}$ & $\mathrm{X}$ & sd & $\mathbf{F}$ & $X$ & sd & $\mathbf{F}$ \\
\hline $0-5,000$ steps & 3.11 & 1.01 & \multirow{3}{*}{$6.712 * *$} & 2.05 & 0.98 & \multirow{3}{*}{$4.958^{*}$} & 2.24 & 1.09 & \multirow{3}{*}{$9.075 * *$} \\
\hline $5,001-10,000$ steps & 3.58 & 0.82 & & 2.39 & 0.98 & & 2.85 & 1.07 & \\
\hline 10,001 steps and above & 3.62 & 1.03 & & 2.57 & 0.99 & & 2.84 & 1.23 & \\
\hline
\end{tabular}

$* \mathrm{p}<.05 ; * * \mathrm{p}<.01$

As can be seen in Table 3, male students' Excessive Focus and Emotion Change, Postponement of Individual-Social Needs and Conflict, and Tolerance Development and Passion average scores are higher than female students. However, only "Tolerance Development and Passion" average scores among these scores are significant $(\mathrm{p}<0.05)$. The number of weekly exercise days of the students was examined, and significant differences were observed in both the Excessive Focus and Emotion Change as well as the Tolerance Development and Passion sub-dimensions. As a result of the Tukey multiple comparison test, it was determined that the average scores of the students exercising 3-5 days a week were significantly higher than the other groups $(p<0.05)$. When the average number of steps taken daily was examined, it was seen that there were significant differences in all three sub-dimensions of exercise addiction. As a result of the Tukey multiple comparison test, it was determined that the average scores of students who took an average of 10,001 steps per day were significantly higher than the other two groups $(\mathrm{p}<0.05)$.

Table 4: Descriptive Statistics on Obesity Awareness and its sub-dimensions (T-test, ANOVA)

\begin{tabular}{|c|c|c|c|c|c|c|c|c|c|}
\hline \multirow[b]{2}{*}{ Gender } & \multicolumn{3}{|c|}{ Obesity Awareness } & \multicolumn{3}{|c|}{ Nutrition Awareness } & \multicolumn{3}{|c|}{ Physical Activity Awareness } \\
\hline & 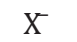 & sd & $\mathbf{t}$ & $X$ & sd & $\mathbf{t}$ & $X^{-}$ & sd & $\mathbf{t}$ \\
\hline Male & 3.06 & 0.44 & \multirow{2}{*}{$-3.320 * *$} & 3.34 & 0.47 & \multirow{2}{*}{-.935} & 3.10 & 0.38 & \multirow{2}{*}{-.390} \\
\hline Female & 3.25 & 0.41 & & 3.39 & 0.43 & & 3.12 & 0.41 & \\
\hline $\begin{array}{c}\text { How many days a week do } \\
\text { you exercise? }\end{array}$ & $X$ & sd & $\mathbf{F}$ & $\mathrm{X}$ & sd & $\mathbf{F}$ & $X$ & sd & $\mathbf{F}$ \\
\hline 0-2 day(s) & 3.17 & 0.44 & \multirow{3}{*}{$3.931^{*}$} & 3.31 & 0.49 & \multirow{3}{*}{$4.754^{*}$} & 3.05 & 0.40 & \multirow{3}{*}{$9.200 * *$} \\
\hline 3-5 days & 3.18 & 0.41 & & 3.50 & 0.34 & & 3.26 & 0.34 & \\
\hline 6-7 days & 2.87 & 0.44 & & 3.29 & 0.44 & & 2.94 & 0.44 & \\
\hline $\begin{array}{c}\text { How many thousand steps } \\
\text { do you take per day? }\end{array}$ & $X$ & sd & $\mathbf{F}$ & $X$ & sd & $\mathbf{F}$ & $X$ & sd & $\mathbf{F}$ \\
\hline $0-5,000$ steps & 3.16 & 0.41 & \multirow{3}{*}{2.015} & 3.32 & 0.41 & \multirow{3}{*}{2.827} & 3.11 & 0.36 & \multirow{3}{*}{.001} \\
\hline $5,001-10,000$ steps & 3.18 & 0.43 & & 3.44 & 0.41 & & 3.11 & 0.40 & \\
\hline 10,001 steps and above & 3.00 & 0.53 & & 3.26 & 0.65 & & 3.11 & 0.51 & \\
\hline
\end{tabular}

As seen in Table 4, average scores of female students' obesity awareness, nutrition awareness and physical activity awareness are higher than male students. However, only "Obesity awareness" average scores among these scores are significant $(\mathrm{p}<0.05)$. The number of weekly exercise days of the students was examined, and it was determined that there were significant differences in obesity awareness sub-dimensions. As a result of the Tukey multiple comparison test, it was determined that the average scores of the students exercising 3-5 days a week were significantly higher than the other groups $(p<0.05)$. When the average number of steps taken daily was analyzed, no significant differences were detected in the three sub-dimensions of obesity awareness. 
Table 5: The Relationship Between Exercise Addiction and Obesity Awareness

\begin{tabular}{|c|c|c|c|}
\hline Scales & & $\begin{array}{c}\text { Exercise } \\
\text { Addiction }\end{array}$ & $\begin{array}{c}\text { Obesity } \\
\text { Awareness }\end{array}$ \\
\hline \multirow{2}{*}{$\begin{array}{c}\text { Exercise } \\
\text { Addiction }\end{array}$} & $\mathrm{r}$ & 1 & .222 \\
\cline { 2 - 4 } & $\mathrm{p}$ & & $\mathbf{. 0 0 0 * *}$ \\
\cline { 2 - 4 } & $\mathrm{n}$ & 249 & 249 \\
\hline \multirow{2}{*}{$\begin{array}{c}\text { Obesity } \\
\text { Awareness }\end{array}$} & $\mathrm{r}$ & .222 & 1 \\
\cline { 2 - 4 } & $\mathrm{p}$ & $\mathbf{. 0 0 0 * *}$ & \\
\cline { 2 - 4 } & $\mathrm{n}$ & 249 & 249 \\
\hline$* \mathrm{p}<.01$ & \multicolumn{2}{|l}{} \\
\hline
\end{tabular}

The correlation analysis results indicate that there is a significant relationship between students' exercise addiction and obesity awareness $(p<0.05$; $\mathrm{r}=.222$ ). When Table 5 is examined, it is understood that this relationship is low and positive. This finding shows that the increase in exercise addiction of students increases awareness of obesity at a low level and positively.

\section{Conclusions and Discussion}

The current study was conducted to examine the relationship between university students' exercise addiction and obesity awareness. It is thought that the research results will contribute to the field of sports sciences.

The normality test results of exercise addiction and obesity awareness scale and sub-dimensions showed that the data had a normal distribution. Besides, considering the average scores of both scales and sub-dimensions, it is understood that students' exercise addiction and obesity awareness are at a medium level. There are studies on the current subject in the literature. In a study, it was determined that the participants' exercise addiction averages were in the risk group (Tekkurşun-Demir \& Türkeli, 2019). In another study, the mean scores of the scale were examined, and it was determined that the participants were within the limit of exercise addiction (İlbak \& Altun, 2020).

In the current study, exercise addictions of male and female students were examined, and it was determined that the scale caused a significant difference in the tolerance development and passion sub-dimension. The tolerance development and passion sub-dimension means desire to exercise and willing to exercise. In this sub-dimension, it shows that men are more willing to exercise in comparison to female students in terms of significant differences in favor of male students. When the literature is examined, elite athletes and students of the faculty of sports sciences are compared. Exercise addiction scores of individuals in both groups were found to be statistically significantly higher than male athletes compared to female athletes. Besides, it was found that exercise addiction levels of men who were students of the faculty of sports sciences were statistically significantly higher than women (Cicioğlu et al., 2019). In a similar study, exercise addiction was examined, and it was determined that the mean score of men was significantly higher compared to women (Tekkurşun-Demir \& Türkeli, 2019). Similarly, exercise addiction was examined with the gender variable, and no significant difference was observed (Köse \& Bayköse, 2019). Exercise addiction was found to have no significant effect on gender (Başaran et al., 2019). Exercise addiction did not have a positive effect on psychological health in both men and women (Jee \& Eun, 2018).

Analyses have shown that only the obesity awareness average scores of female students differ significantly compared to male students. This finding indicates that women have higher obesity awareness than men. In the literature, it is examined whether gender affects obesity. It was determined that the obtained results did not create a statistically significant difference between factor scores (Arslan et al., 2020).

The number of weekly exercise days of the students was examined, and significant differences were observed in both the Excessive Focus and Emotion Change as well as the Tolerance Development and Passion sub-dimensions. In the sub-dimensions of Excessive Focus and Emotion Change, which means loving exercise, to be happy to exercise, and Tolerance Development and Passion, which means be willing to exercise, differed in favor of those who exercise 3-5 days a week. This finding shows that exercising 3-5 days a week makes the students happier. In a study, $3.7 \%$ of individuals who performed regular physical activity at least 3 days a week or more had exercise addiction, and $37.10 \%$ showed signs of exercise addiction (Yıldırım \& Yıldırım, 2016). 
It was determined that there was a significant relationship between students' exercise addiction and obesity awareness when the correlation analysis was examined. It is understood that the relationship obtained is low and positive. This finding shows that the increase in exercise addiction of students increases awareness of obesity at a low level and positively. There are studies in the literature supporting the correlation result of the current study. It has been determined that there is a positive relationship between exercise addiction and diet, eating attitude and behavior of individuals doing regular physical activity (Yıldırım et al., 2017). A similar result was obtained in determining the relationship between exercise addiction and mental endurance in sports. The result obtained showed that there was a significant relationship between both variables (Tekkurşun-Demir \& Türkeli, 2019). It was determined that the relationship between perception of boredom in free time and exercise addiction was not significant (Köse \&Bayköse, 2019). There is no significant relationship between exercise addiction and happiness and life satisfaction (Başaran et al., 2019). When the results of another study were analyzed, it was found that there was a relationship between participants' physical activity levels and obesity awareness levels (Yüksel \& Akıl, 2019).

\section{Ethics Approval and Informed Consent}

Ethics approval and informed consent: Informed consent of participants was obtained, and they were at liberty to participate and withdraw voluntarily. We also ensured that their responses were anonymous and confidential.

\section{References}

Adams, Jeremy. "Understanding Exercise Dependence." Journal of Contemporary Psychotherapy, vol. 39, 2009.

Allen, Amy. Effects of Educational Intervention on Children's Knowledge of Obesity Risk Factors. Carroll College, 2011.

Arslan, Miray, et al. "Awareness of Pharmacy Faculty Students Towards Obesity." Lokman Hekim Dergisi, vol. 10, no. 2, 2020, pp. 171178.

Başaran, Z., et al. "Examination of Exercise
Addiction, Happiness and Life Satisfaction of Persons Continuing to Fitness Centers in terms of Personal Characteristics." International Conference on Sports for all and Wellness, 2019.

Bavl1, Özhan, et al. "Investigation the Effects of Participation Regular Exercise on Exercise Dependence." Selçuk University Journal of Physical Education and Sport Science, vol. 13, no. 2, 2011, pp. 150-153.

Bayraktar, Aygin. "Obezite Tedavisinde Eczacının Rolü ve Katkısı." Mised, 2010.

Cicioğlu, Halil İbrahim, et al. "Exercise Addiction Levels among Elite Level Athletes and Students of Sports Sciences Faculty." Journal of Dependence, vol. 20, no. 1, 2019, pp. 1220.

Cortina, Jose M. "What is Coefficient Alpha? An Examination of Theory and Applications." Journal of Applied Psychology, vol. 78, no. 1, 1993, pp. 98-104.

Hausenblas, Heather A., and Danielle Symons Downs. "Exercise Dependence: A Systematic Review." Psychology of Sport and Exercise, vol. 3, no. 2, 2002, pp. 89-123.

İlbak, İsmail, and Mehmet Altun. "Investigation of Exercise Addiction Levels of Non-Sedentary Persons." Çomü Spor Bilimleri Dergisi, vol. 3, no. 1, 2020, pp. 11-19.

Jacobs, Eric Jacobs, et al. "Waist Circumference and all-Cause Mortality in a Large us Cohort." Archives of Internal Medicine, vol. 170, 2010.

Jee, Yong-Seok, and Denny Eun. "Exercise Addiction and Psychophysiological Health in Korean Collegiate Students." International Journal of Mental Health and Addiction, vol. 16, 2018, pp. 451-465.

Kafkas, M. Emin, and Gokmen Özen. "The Turkish Adaptation of the Obesity Awareness Scale: A Validity and Reliability Study." Inönü University Journal of Physical Education and Sport Sciences, vol. 1, no. 2, 2014.

Köse, Elif, and Nazmi Bayköse. "Examination of the Correlation Between Leisure Boredom and Exercise Dependence." Mediterranean Journal of Sport Science, 2019.

Lee, Pi-Hsia, et al. "Perceptions of Exercise in Obese 
School-Aged Children." Journal of Nursing Research, vol. 17, no. 3, 2009, pp. 170-176.

Lim, Crystal S, et al. "Depressive Symptoms, Ethnic Identity, and Health-Related Quality of Life in Obese Youth." Journal of Pediatric Psychology, vol. 41, 2015, pp. 441-452.

Murphy, Maureen, and Barbara Polivka. "Parental Perceptions of the School's Role in Addressing Childhood Obesity." The Journal of School Nursing, vol. 23, 2007, pp. 40-46.

O'dea, Jennifer A., and Rachel Wilson. "SocioCognitive and Nutritional Factors Associated with Body Mass Index in Children and Adolescents: Possibilities for Childhood Obesity Prevention." Health Education Research, vol. 21, 2006, pp. 796-805.

Özer, Kamil. Fiziksel Uygunluk. Nobel Publishing, 2013.

Pitta F., et al. "Quantifying Physical Activity in Daily Life with Questionnaires and Motion Sensors in COPD." European Respiratory Journal, vol. 27, no. 5, 2006.

Streiner, David. "Starting at the Beginning: An Introduction to Coefficient Alpha and Internal Consistency." Journal of Personality Assessment, vol. 80, no. 1, 2003, pp. 99-103.

Tabachnick, Barbara G., and Linda S. Fidell. Using Multivariate Statistics. Pearson, 2013.
Tam, Abbas, and Bekir Çakır. "Approach of Obesity in Primary Health Care." Ankara Medical Journal, vol. 12, no. 1, 2012, pp. 37-41.

Tekkurşun-Demir, Gonul, and Anil Türkeli. "Examination of Exercise Addiction and Mental Strength Levels of Students of Sport Sciences Faculty." Journal of Sport Sciences Researches, vol. 4, no. 1, 2019, pp. 10-24.

Tekkurşun-Demir, Gonul, et al. "Exercise Addiction Scale (EAS): A Study of Validity and Reliability." Kastamonu Education Journal, vol. 26, no. 3, 2018, pp. 865-874.

Yildırım, İrfan, et al. "Correlation between Exercise Dependence and Eating Attitudes and Behaviors." $C B \ddot{U}$ Beden Eğitimi ve Spor Bilimleri Dergisi, vol. 12, no. 1, 2017, pp. 4354.

Yıldırım, Y., and I. Yıldırım. "Exercise Addiction Depression Relation." International Conference on the Changing World and Social Research, 2016.

Yüksel, Elif, and Mustafa Ak1l. "Investigation of the Correlation between the Physical Activity Levels of Adolescents and their Awareness about Obesity and Nutritional Behaviors." Niğde Üniversitesi Beden Eğitimi ve Spor Bilimleri Dergisi, vol. 13, no. 3, 2019, pp. 185-193.

\section{Author Details}

Samet Zengin, Trabzon University,Turkey, Email ID: serkanzengir@trabzon.edu.tr

Fatih Kırkbir, Karadeniz Technical University,Turkey, Email ID: fatihkirkbir@gmail.com 